\title{
Ergonomic and efficiency analysis of conventional apple harvest process
}

\author{
Zhao Zhang ${ }^{1}$, Yuanjie Wang ${ }^{2 *}$, Zhaohua Zhang ${ }^{3 *}$, Dapeng $\mathrm{Li}^{4}$, \\ Zhengze $\mathrm{Wu}^{5}$, Rui Bai ${ }^{6}$, Guangfu Meng ${ }^{7}$ \\ (1. Department of Agricultural and Biological Engineering, Pennsylvania State University, University Park, PA 16802, USA; \\ 2. Agricultural Information Institute, Chinese Academy of Agricultural Sciences, Beijing 100081, China; \\ 3. College of Economics and Management, Shandong Agricultural University, Tai'an 271018, Shandong, China; \\ 4. Shanghai Nuclear Engineering Research and Design Institute, Shanghai 200233, China; \\ 5. Jiana Real Estate Development Company, Dezhou 253000, Shandong, China; \\ 6. Huafa Real Estate Development Company, Weihai 264200, Shandong, China; \\ 7. TianJinXi Railway Station, China Railway Beijing Group Co., Ltd., Dezhou 253000, Shandong, China)
}

\begin{abstract}
Apples are still manually harvested by workers using ladders and buckets. Though it is known that manual apple harvest would probably lead to occupational injuries (e.g., back, neck, and shoulder strains), there has been little research that focuses on identifying the awkward activities/postures of pickers during the harvest process. After categorizing apple harvest work into 12 activities, this study used the method of Rapid Upper Limb Assessment (RULA) to identify awkward postures/activities that occurred during apple harvest. Awkward activities confirmed include descending a ladder, dumping apples, picking high and low apples on a ladder as well as on the ground, and moving a ladder, with potential reasons for each awkward activity provided. Meanwhile, it was demonstrated that pickers spent approximately $64 \%$ of working time under awkward postures that would lead to occupational diseases. In addition, this study analyzed picker harvest efficiency in terms of general and detail manners. The general mode assessed harvest activity in terms of picking and non-picking, with results showing that pickers averagely spent $76 \%( \pm 7 \%)$ of harvest time in picking apples. Further analysis evaluated picking activities in terms of reaching, detaching, and transporting apples, with results showing that pickers spent averagely $30 \%( \pm 6 \%)$ of time in detaching apples, which is the value time during apple harvest. Furthermore, valuable picking time ratio was obtained as the multiplication of picking time ratio and detaching time ratio. With a valuable ratio of $22 \%( \pm 5 \%)$, it theoretically demonstrated the low harvest efficiency of the traditional harvest method. Since a majority of the awkward activities and the low efficiency were because of the ladders/buckets, using a harvest-assist unit may be a potential solution. Additionally, more efforts should be spent on the development of innovative mechanism to replace worker in placing attached apples to the bucket. Once the time for transporting apples is eliminated, the time for reaching apples is also removed, indicating the harvest efficiency would be improved significantly.
\end{abstract}

Keywords: rapid upper limb assessment, awkward postures, apple harvest, safety, ergonomic analysis, harvest efficiency analysis DOI: $10.25165 /$ j.ijabe.20191202.4567

Citation: Zhang Z, Wang Y J, Zhang Z H, Li D P, Wu Z Z, Bai R, et al. Ergonomic and efficiency analysis of conventional apple harvest process. Int J Agric \& Biol Eng, 2019; 12(2): 210-217.

\section{Introduction}

Apples, due to their susceptibility to bruising and lack of appropriate harvest technologies, are still manually harvested worldwide $^{[1]}$. Researchers have been working on developing apple harvest robots for decades to fully replace human labor, and

Received date: 2018-08-04 Accepted date: 2018-12-19

Biographies: Zhao Zhang, $\mathrm{PhD}$, Research Assistant, research interests: automated agricultural machinery systems and smart agriculture, Email: zznwsuaf@163.com; Dapeng Li, MS, Water Resource Engineer, research interests: water resource management and utilization, Email: lidapeng@ snerdi.com.cn; Zhengze Wu, BS, Civil Engineer, research interest: real estate management, Email: zhibin9570@163.com; Rui Bai, BS, Water Resource Engineer, research interest: water resource management and utilization, Email: 303980132@qq.com; Guangfu Meng, BS, Civil Engineering, research interest: Civil Engineering Management, Email: 155205687@qq.com.

*Corresponding author: Yuanjie Wang, $\mathrm{PhD}$, research interests: agricultural information and journal open access publishing. Agricultural Information Institute, Chinese Academy of Agricultural Sciences, Beijing 100081, China. Tel: +86-10-82109657, Email: wangyuanjie@caas.cn. Zhaohua Zhang, PhD, Lecturer, research interest: health economics and public health. Shandong Agricultural University, Tai'an 271000, Shandong, China. Tel: +86-5388249261, Email: zzhang@sdau.eud.en. actually several prototypes of harvest robots have been developed $^{[2-9]}$. However, on the commercial stage, beyond the strawberry harvest robotics, there are no other robots for apple or other fruit harvest, because of their high cost, low efficiency, and fruit bruising issue, the robots are still far from being commercially adopted by growers ${ }^{[10-17]}$. The recently emerged harvest-assist platform technology, which could increase picking efficiency and alleviate occupational injuries, seems an option to assist with pickers ${ }^{[18,19]}$. However, since their high cost and bruising issue, harvest platforms are slow in being adopted by growers ${ }^{[19-23]}$. Therefore, currently, workers harvest apples, the same as decades ago, by wearing a bucket during the entire harvest process for temporary holding of apples, and when the bucket is full (approximately $20 \mathrm{~kg}$ ), workers walk to a bin, where they stoop down to release the harvested apples ${ }^{[24]}$. Since workers need to use ladders extensively to reach high apples, moving ladders is a must during the harvest process ${ }^{[25]}$. Considering a ladder weighing about $15-25 \mathrm{~kg}$, the task of moving ladders requires strength considerably. Moreover, frequently climbing and descending a ladder is already strength demanding, not to mention to carry a heavy bucket continuously ${ }^{[26]}$. Workers have to do overhead work to reach high apples above the height of their 
shoulders, which is awkward and uncomfortable ${ }^{[26,27]}$. It is therefore empirically concluded that the apple harvest work consists of a lot of awkward activities (e.g., stretching body to reach apples, stooping down for apple release, and overheard work), and studies have confirmed these awkward activities to be significantly associated with occupational injuries (e.g., musculoskeletal disorders of the upper limbs ${ }^{[28-32]}$.

Researchers noticed decades ago that the conventional apple harvest method is not only low in efficiency but also prone to causing occupational injuries. However, existing studies analyze apple process in a preliminary and crude manner, by assessing the pickers' activities in a general mode (e.g., time ratio of upper arm above the head $)^{[29,33]}$. To some extent, these studies were meaningful, but they did not evaluate the body posture in a systematical approach. Since it has been reported the apple harvest work would potentially cause issues to back and arm, methods without considering all these factors would be invalid.

The Rapid Upper Limb Assessment (RULA) method, which evaluate body postures in a detailed manner (e.g., arm, load, back, legs, upper/lower arms, neck, trunk, and wrist with its twist) was developed and validated ${ }^{[34,35]}$, which would be a proper tool to assess picking postures. The RULA method as a fast observation approach was used to inspect children's computer-related posture $^{[35]}$. Experimental results showed the validation of RULA method for both intra-rater and inter-rater reliability. The study also demonstrated the RULA was more reliable for assessment of older children than younger kids. Researchers used RULA method to evaluate postural risks of children in school settings ${ }^{[36]}$. Results showed neither significant differences in RULA outcome scores nor in visual search strategies between groups was found, indicting the usefulness of this method. The RULA method was applied to assess workers' postures in a ceramic industry and have its reliability proven ${ }^{[37]}$. In addition, the RULA method's validity has been demonstrated by using it to analyzing dental students' postures $^{[38-44]}$.

In addition, previously conducted research categorized apple harvest activities in a rough manner, such as picking apples, and handling ladders. For the apple harvest, the postures for picking high apples should be significantly different from picking low apples, which is not involved with overhead work. The handling ladder categorization is also too general, as moving ladders are entirely different from climbing up ladders. So, there requires a re-categorization of the apple harvest process in a more detailed manner.

Harvest efficiency is a concerned factor for the conventional apple harvest process by apple growers. With gradually tightening labor pool and increasing labor cost, the U.S. apple industry's competitiveness is decreasing nationally and internationally. Since more than $50 \%$ of the apple production cost is due to the harvest labor, it is therefore important to maintain its competitiveness by increasing labor's harvest efficiency. Though a few studies have been conducted in analyzing harvest efficiency, the research was very preliminary and unsystematic. Thus, few studies were conducted to theoretically analyze the conventional apple harvest process. The meaning of the analysis is to direct the research direction to find the efficiency improvement room for conventional apple harvest method.

Time and Motion Study (TMS), initiated in the early 20th and defined as a scientific analysis method designed to determine the best way to execute a task and to measure the time allocations of workers in conducting different activities, has been used extensively in improving workers' efficiency and productivity ${ }^{[45-47]}$. TMS was applied to the work process of 767 nurses in 36 different hospitals and identified main areas for the efficiency improvement on nursing care ${ }^{[48]}$. Workers' producing process on a lamp assembly line was analyzed using TMS, and the improved working process increased workers' efficiency by approximately $15 \%{ }^{[49]}$. Worker' efficiency was assessed using TMS and indicated there was $53 \%$ room for the productivity improvement ${ }^{[50]}$. Workers' time-wasting activities were identified using TMS in a production line of lady bags, and by adopting the newly improved working procedure with redundant activities eliminated, the productivity was improved by $13 \%^{[51]}$. The TMS has been used extensively in industry domain to increase work efficiency, and it is also a proper tool to be used to conduct efficiency analysis for apple harvest process.

This paper first introduced the RULA method by using an example to explain the detailed evaluation procedure, after which the apple harvest process was categorized into a more detailed manner, compared to the existing general format. Then, the conventional apple harvest process was evaluated in terms of the detailed categorization, with the injury-inducing activities identified. Finally, the efficiency analysis on the conventional apple harvest method was conducted using the time and motion study method.

\section{Materials and methods}

\subsection{RULA method and evaluation procedure}

The Rapid Upper Limb Assessment (RULA) tool, as a subjective inspection method, is used in this study to evaluate apple harvest process from an ergonomic perspective (Figure 1). Table A is the RULA worksheet, based on which a posture can be inspected. The RULA method first conducts arm and wrist analysis by considering factors of upper arm/lower arm/wrist position and wrist twist, after which the Posture Score A was obtained (Table A in Figure 1). After adding the Posture Score A, Muscle Use Score, and Force/load Score, the Wrist \& Arm Score is determined. The Posture B score was calculated by taking neck, trunk, and leg positions into account. After combining the Posture B Score, Muscle Use Score, and Force/Load Score, the Neck/Trunk/Leg score is gained. By inputting the Wrist and Arm Score and Neck/Trunk/Leg Score into Table C, the RULA Grand Score was generated, with its indication shown (Table 1). When larger then 5, it suggests this posture would cause safety issue.

A worker's posture while standing on a ladder for picking is used to describe the RULA evaluation process (Figure 2). Since the angle between the vertical line and upper arm is about $40^{\circ}$ (A in Figure 1), the Upper Arm Score is 2 . As the lower arm angle is around $95^{\circ}$ (D in Figure 2), the Lower Arm Score is 1. Though the wrist is blocked by leaves, based on the author's picking experience and mimicking the posture, it is reasonably estimated the Wrist Score is 2. By inputting Upper Arm Score, Lower Arm Score, and Wrist Score into Table A, the Posture Score A is generated as 3. Since this posture is repeated more than 4 times in a minute (Muscle Use Score as 1), and static load is estimated between 4.4-22 lbs (Force/Load score as 2), the Wrist \& Arm Score is gained as 6 . Considering the neck angle is $5^{\circ}(\mathrm{C}$ in Figure 2) and trunk angle is $15^{\circ}$ (B in Figure 2), and legs are supported (Leg Score of 1), the Posture B Score is calculated as 2, based on which the Neck/Trunk/Leg Score is calculated as 4. By combining Neck/Trunk/Leg Score and Wrist/Arm Score, the RULA Grand Score (RGS) was finally determined as 6 (Table C in Figure 1), suggesting this posture would incur occupational diseases (Table 1). 


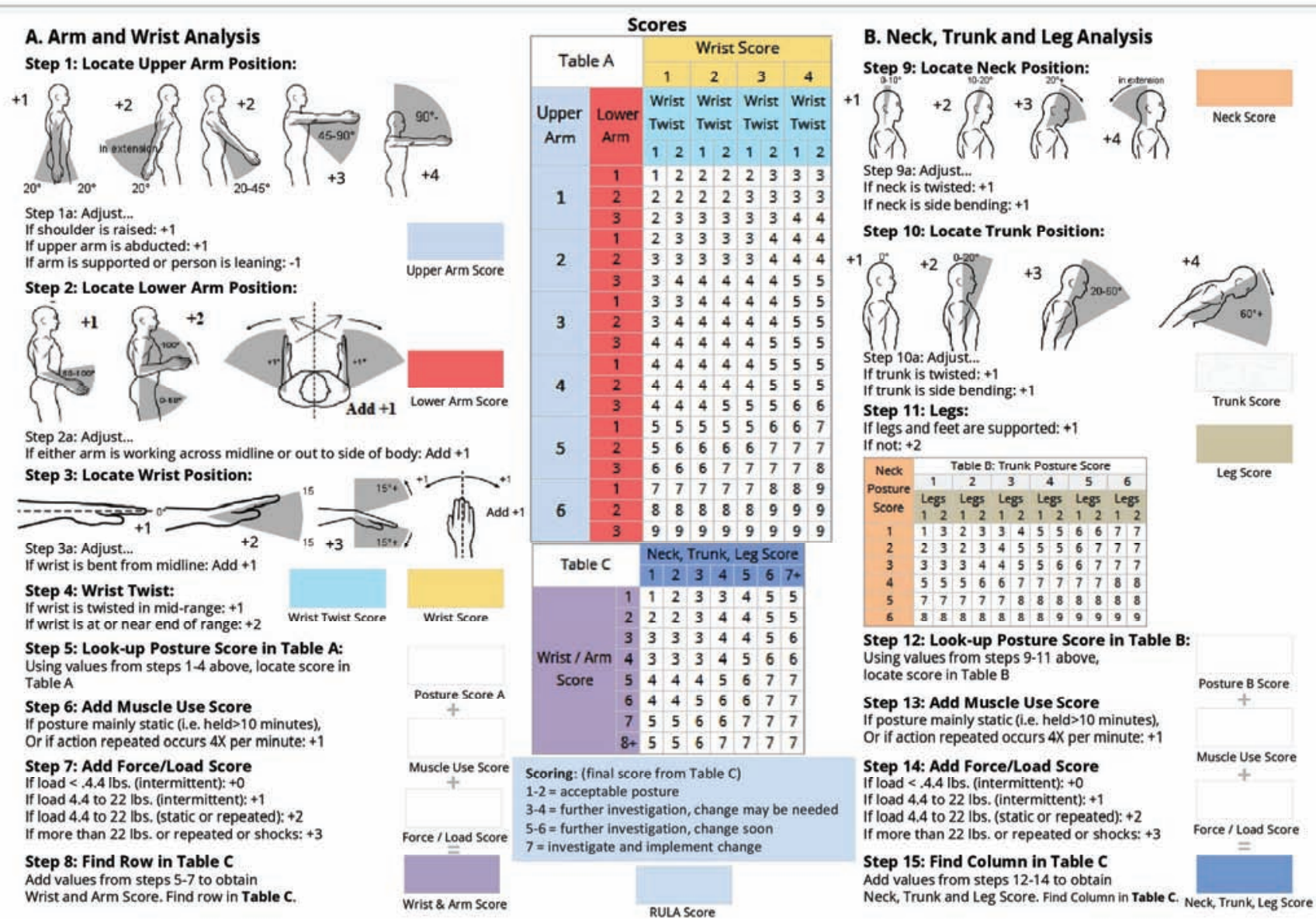

Figure 1 Rapid upper limb assessment worksheet ${ }^{[34,35]}$

Table 1 Rapid Upper Limb Assessment (RULA) levels and indications $^{[34,35]}$

\begin{tabular}{lclc}
\hline $\begin{array}{c}\text { RULA } \\
\text { Grand } \\
\text { Score }\end{array}$ & $\begin{array}{c}\text { Action } \\
\text { Level }\end{array}$ & Indications & $\begin{array}{c}\text { Inducing } \\
\text { occupational } \\
\text { injuries? }\end{array}$ \\
\hline 1 or 2 & 1 & The posture is safe. & No \\
3 or 4 & 2 & Further evaluations and changes may be needed. & No \\
5 or 6 & 3 & Action needs to be taken. & Yes \\
7 or more & 4 & Action needs to be taken immediately. & Yes \\
\hline
\end{tabular}

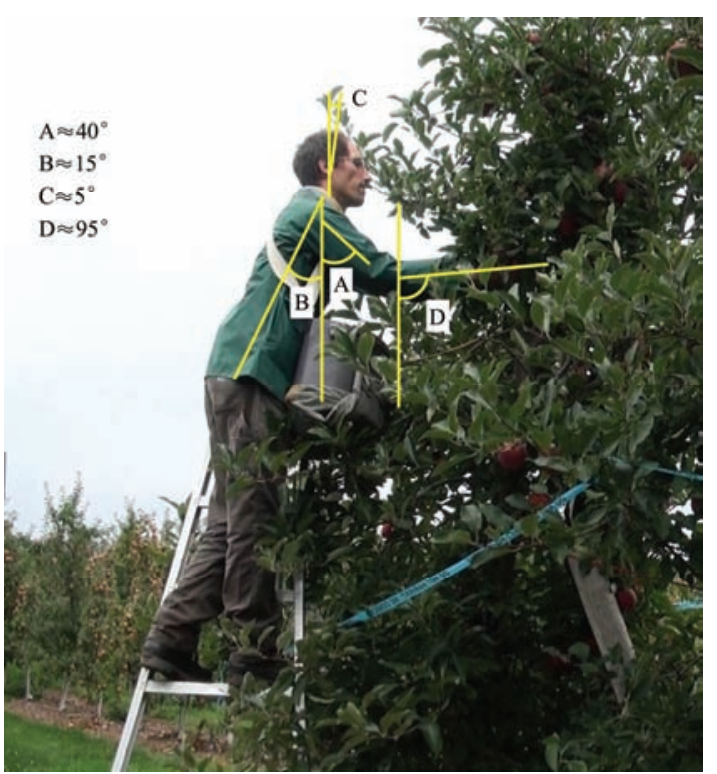

Figure 2 A worker posture by standing on a ladder for apple picking

\subsection{Time and motion analysis of harvest efficiency}

In this study, the time and motion analysis was conducted in terms of general and detailed investigations.

The general harvest process analysis focuses on the whole harvest process, aiming at quantifying time allocations of different harvest activities (e.g., picking and non-picking). Based on Table two, the picking activities include picking low, middle, and high apples on ground, as well as on the ladder; all other 6 activities in Table 2 were grouped as non-picking.

The detailed analysis focuses on further evaluation of the picking activity (generated from general analysis) by categorizing them into three individual activities as of reaching, detaching, and transporting, with detaching as the most valuable. The reaching is after pickers' hand leaving the bucket until getting to fruit on the tree; the detaching is detaching fruit from the tree branches, from the hands contacting an apple till the apple physically separated from the branch; the transporting is after the fruit is independent from the tree till they are put into bucket. Detaching is the most valuable activity in apple harvest, and higher time ratio of detaching is desirable. Time allocation, instead of real time, of the three activities for different pickers would be compared. Harvest efficiency is always a concern of apple growers.

Based on the general and detailed analysis, the valuable time ratio would be obtained as the multiplication of picking time ratio and detaching time percentage. The valuable time ratio could reflect the actual harvest efficiency.

\subsection{Video recording and frame extraction}

Trees of two apple cultivars were studied in this research, 'Gala' and 'Fuji'. In the first experiment, 10 'Gala' apple trees (mean height $337 \pm 25 \mathrm{~cm}$ ) were manually harvested by two pickers 
(mean height $179 \pm 6 \mathrm{~cm}$ ), as identified picker one and picker two. In the second experiment, 30 'Fuji' apple trees (mean height $265 \pm 20 \mathrm{~cm}$ ) were hand-harvested by another two pickers (mean height $174 \pm 1 \mathrm{~cm})$, picker three and picker four. The tree row width is about $4.3 \mathrm{~m}$ (14 feet), and the tree in-row width is about $1.2 \mathrm{~m}$ (4 feet).

In experiment one, each picker harvested five 'Gala' trees, during which they only picked apples from the side facing them, as supporting wires going through the center of the apple canopies preventing pickers from moving to the other side (the same as real picking condition). While harvest progressing, the process was filmed with a video camera. The video recording person was required to always keep the camera at eye-height in order to keep the same observing angle. In experiment two, each picker harvested 15 'Fuji' trees. All other settings, requirements, and video recording procedures were exactly the same as that in experiment one. During the video recording process, the camcorder person needs to video record at one side of the person, trying best to keep at least one side of the arms visible.

This research focuses on identifying the hazardous activities by evaluating postures. Since an activity consists of postures, and through evaluating each posture, the activity was assessed. To avoid missing activities, in this study, frames were extracted at the frequency of 2 fps.

Due to block resulting from leaves or branches/limbs or body trunk, in one frame, arms may be partially or even fully invisible. In this study, only the more visible side of arms is assessed, since the arm difference would not affect the RULA Grand Score ${ }^{[20]}$. If both arms are not visible (this seldom happens), the author would simulate the picking posture according to picking experience and then use the best estimation. Since the person evaluating the frames had extensive experience in manual apple harvest, the estimation is reasonable.

\section{Results and discussion}

\subsection{Categorization of apple harvest activities}

Compared to the general apple harvest activity categorization (4 items in Table 2) used extensively in previous research, this study provides a new and more detailed categorization method (12 items in Table 2). The previous manner only considers picking as one item, but in the newly developing approach, the picking is divided into six detailed items as picking low apples, middle, and high apples on ground or ladder. For a person standing still with the bucket shoulder strap looped once over each shoulder and crossed at the back, apples below the canvas bottom of the bucket are the low ones, fruit above the canvas bottom of the bucket but below the shoulder-height of the picker are middle apples, and those above the shoulder-height are the high apples. For the low apples, pickers need to bend for picking; for the high apples, workers need to lift their arms about shoulders for picking; for the middle apples, they can pick in a relatively more comfortable manner.

This more detailed categorization could be used for better assess harvest activities in a more detailed manner. Furthermore, the previous emptying bag activity is further divided into three detailed items as walking to the bin, dumping apples, and walking away from the bin. This provides more detailed information, as walking away from the bin (empty bucket) is less strength demanding compared to walking to the bin (full bucket). Additionally, handling ladder is separated into three sub-items as climbing up and down the ladder, and moving a ladder, as each activity is different from others.

\section{Table 2 New apple harvest activity categorization compared} to previous one

\begin{tabular}{|c|c|}
\hline $\begin{array}{l}\text { Previous apple harvest activity } \\
\text { categorization }{ }^{[33]}\end{array}$ & New apple harvest activity categorization \\
\hline Picking task & Picking low apples (ground) \\
\hline Emptying bag & Picking middle apples (ground) \\
\hline Handling ladder & Picking high apples (ground) \\
\hline \multirow[t]{9}{*}{ Other tasks } & Moving the ladder \\
\hline & Climbing up the ladder \\
\hline & Picking low apples (ladder) \\
\hline & Picking middle apples (ladder) \\
\hline & Picking high apples (ladder) \\
\hline & Climbing down the ladder \\
\hline & Walking to the bin \\
\hline & Dumping apples \\
\hline & Walking away from the bin \\
\hline
\end{tabular}

\subsection{General results of apple harvest process assessment}

In total, 14191 frames $(3238,6316,2896$, and 1741 frames for picker one, two, three, and four, respectively) were inspected in this research. Each frame was first categorized into one of the 12 items (Table 2) and then RULA evaluated (Figure 1), resulting in a RULA Grand Score (GRS). Table 3 shows different pickers' RGS and time percentage under each categorized activity. Literally, activities with the RULA Grand Score greater than or equal to 5 are considered as leading to occupational diseases.

\subsection{Occupational injury-inducing activities during apple harvest}

Based on Table 3, the awkward activities are identified and the potential reasons for these awkward postures are shown in Table 4 and Figure 3.

The RGS of picking low apples on ground (5.6) would be harmful for health. The reason is because the picker has to stoop significantly down to get access to apples. For those long limbs, it was observed that pickers first bend down to grab the limb and then stand to the normal position, after which they use one hand to hold the limb and the other hand to detach apples. Thus, one potential solution is to keep the low apple tree limbs long. The other potential solution for this issue is to collaborate with horticultural scientists to eliminate the very low limbs.

The picking high apples on ground (RGS of 5.6) needs attention. In order to reach high apples, pickers have to lift their arms, and work overhead. This is not only harmful for upper limbs, but also causes uncomfortable postures for the neck because in order to get a better vision perspective, the picker may need to tilt the head backwards. In addition, stretching body to some extreme postures is a must to pick further apples. Picking high apples on ladder is even worse (RGS of 5.6) because the ladder constrains the pickers' movement. Therefore, the picker may need to use even more extreme conditions to grab a further apple, in which condition the feet may not be evenly supported by the ladder rungs.

The activity of moving the ladder is most harmful activity, considering it has the largest RGS of 6.2. First of all, the ladder itself is very heavy, about $15-25 \mathrm{~kg}$. Considering the picker has already carried a heavy bucket, moving a $20 \mathrm{~kg}$ ladder is never an easy task. Second, the orchard terrain is uneven, and thus, the picker may not be well supported. 
Table 3 Different pickers' RULA Grand Score (RGS) and time percentage (TP) under each categorized activity

\begin{tabular}{|c|c|c|c|c|c|c|c|c|c|c|}
\hline \multirow{2}{*}{ Activity } & \multicolumn{2}{|c|}{ Worker 1} & \multicolumn{2}{|c|}{ Worker 2} & \multicolumn{2}{|c|}{ Worker 3} & \multicolumn{2}{|c|}{ Worker 4} & \multicolumn{2}{|c|}{ Average } \\
\hline & RGS & $\mathrm{TP} / \%$ & RGS & $\mathrm{TP} / \%$ & RGS & $\mathrm{TP} / \%$ & RGS & $\mathrm{TP} / \%$ & RGS & $\mathrm{TP} / \%$ \\
\hline Pick low apples (ground) & 5.3 & 10.5 & 5.7 & 8.8 & 5.8 & 8.6 & 5.8 & 5.3 & 5.6 & 8.3 \\
\hline Pick middle apples (ground) & 4.3 & 10.6 & 4.1 & 20.0 & 4.5 & 17.2 & 4.6 & 27.8 & 4.4 & 18.9 \\
\hline Pick high apples (ground) & 5.7 & 17.8 & 5.6 & 15.1 & 5.8 & 9.0 & 5.4 & 8.5 & 5.6 & 12.6 \\
\hline Move ladder & 6.2 & 3.1 & 5.9 & 2.9 & 6.4 & 6.7 & 6.3 & 5.5 & 6.2 & 4.6 \\
\hline Pick low apples (ladder) & 5.6 & 0.2 & 5.8 & 0.3 & N/A & N/A & N/A & N/A & N/A & N/A \\
\hline Pick middle apples (ladder) & 4.4 & 23.5 & 4.5 & 27.0 & 4.6 & 27.0 & 4.8 & 25.5 & 4.6 & 25.8 \\
\hline Pick high apples (ladder) & 5.8 & 18.1 & 5.7 & 12.1 & 5.6 & 9.1 & 5.3 & 2.2 & 5.6 & 10.4 \\
\hline Climb down ladder & 5.1 & 2.4 & 5.2 & 3.5 & 5.2 & 5.2 & 4.8 & 6.7 & 5.1 & 4.5 \\
\hline Walk to bin & 4.9 & 2.4 & 4.7 & 1.8 & 5.0 & 3.1 & 5.0 & 3.9 & 4.9 & 2.8 \\
\hline Dump apples & 5.2 & 4.4 & 5.1 & 4.5 & 5.5 & 5.2 & 5.8 & 4.7 & 5.4 & 4.7 \\
\hline
\end{tabular}

Note: N/A means this activity does not occur.

Table 4 Occupational injury-inducing activities and potential reasons

\begin{tabular}{ll}
\hline \multicolumn{1}{c}{ Occupational injury-inducing activities } & Potential reasons \\
\hline Picking low apples (ground) & Pickers need to stoop or bend to reach low apples \\
Picking high apples (ground) & Pickers need to stretch body to reach high apples \\
Moving the ladder & The ladder is heavy, with arms abducted and wrist twisted to hold a ladder \\
Picking low apples (ladder) & Pickers need to stoop or bend to reach low apples (this occurs rarely) \\
Picking high apples (ladder) & Pickers need to stretch body, and keep balance on a ladder \\
Climbing down the ladder & Pickers hold the partially or fully filled bucket and keep balance on a ladder \\
Dumping apples & Pickers need to bend to release apples into the bin
\end{tabular}
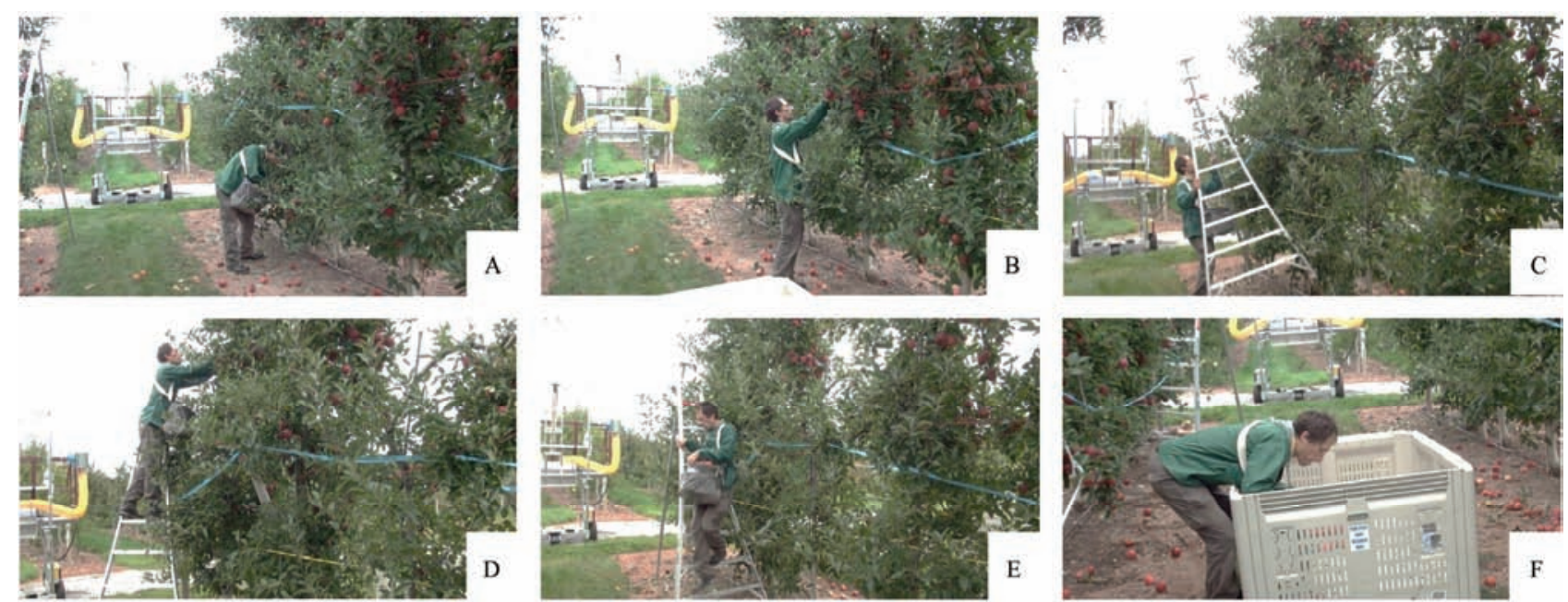

Figure 3 Photos of a worker conducting occupational injury-inducing activities during apple harvest (A: picking low apples on ground;

B: picking high apples on ground; C: moving ladder; D: picking high apples on ladder; E: climbing down ladder, F: dumping apples)

The RGS (5.1) of climbing down the ladder is $6 \%$ larger than the GRS (4.8) of climbing up the ladder activity. Two potential reasons are: 1) pickers have a bucket filled with more apples when they climb down the ladder than climbing up the ladder; and 2) pickers can see the rungs when climbing up, while not when climbing down, in which way their body mass may not be evenly supported.

Dump apples (RGS of 5.4) also leads to health issues, and the reason is that before releasing apples into the bin, the bucket is usually full $(20 \mathrm{~kg})$. Moreover, the bending down is significant, and could even go about $90^{\circ}$, in which way it is difficult for workers to control his body movement.

Figure 4 shows four pickers' time percentage under RGS above 5. Generally, all pickers have above $60 \%$ of time spent on occupational injury-inducing activities, ranging from $60.5 \%$ to $69.4 \%$. The average time percentage of $63.5 \%$ quantitatively indicates the apple harvest work is hazardous and harmful for health. It can be summarized that a majority of occupational injury-inducing activities are relate to ladders, including standing on the ladder for picking and moving a ladder. By eliminating these activities, their associated occupational diseases should be removed. Adoption of harvest platforms (several are commercialized) may be a solution to alleviate the occupational injuries ${ }^{[25-28]}$. Continuous research is being conducted to develop methods that could reduce the awkward postures and loads on the apple pickers. For example, hip belt usage with apple buckets in the laboratory was assessed and demonstrated that it reduced muscle activity ${ }^{[33]}$. 


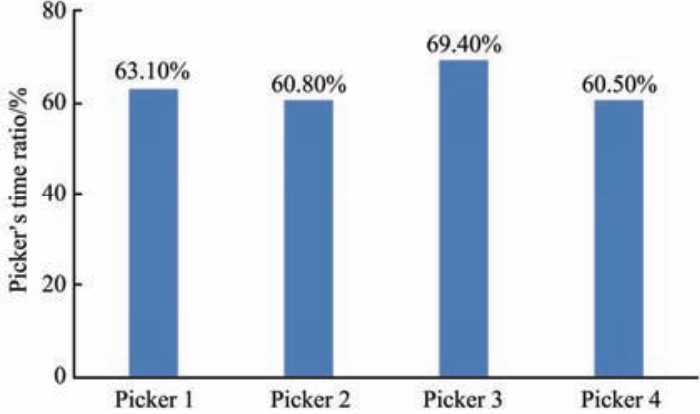

Figure 4 Picker's time ratio under RGS $>5$

\subsection{Safety activities during apple harvest}

A change is not needed for picking middle apples for both on the ground (RGS 4.4) and ladder (RGS 4.6). A potential reason for ground RSG $4 \%$ lower than that for ladder is that pickers can move easily on the ground. For some apples that pickers can move a tiny step to reach and avoid awkward postures when on the ground, workers have to stretch or bend much more to get access to when standing on the ladder.

The RGS of walking away from the bin (4.3) is $12 \%$ lower than that of walking to the bin (4.9). The only difference between the two activities is that the bucket is empty for the former activity, while fully filled for the latter, and the difference is around $20 \mathrm{~kg}$. In addition, this weight of $20 \mathrm{~kg}$ is one important reason that the labor pool for apple harvest is limited, because not all agricultural employees can sustain this load for a long time. Considering having a static load (i.e., wearing a bucket) during the entire harvest process causes health issues, a few harvest platforms using vacuum or conveyor to transport apples to free workers from carrying the bucket have been developed and commercialized.

\subsection{General harvest process analysis}

The general harvest process analysis results are shown in Figure 5. Among the 4 pickers, the picking time ratio ranges from $69 \%$ to $83 \%$, with the average of $76 \%( \pm 7 \%)$. Picker 2 had the highest value in picking time ratio $(83 \%)$ could potentially be explained by the fact that the pick spent more time in picking low level apples. On the contrary, Picker 4 had the lowest value in picking time ratio $(69 \%)$ could be explained by the fact that this person spent more time in harvesting high level apples, so a certain amount of time was used by moving/climbing/descending ladders.

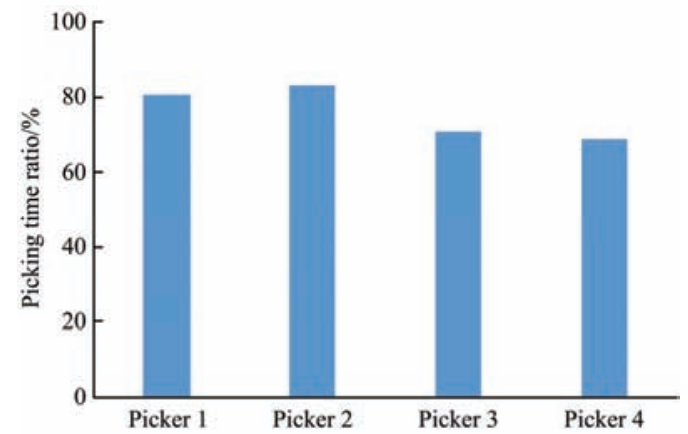

Figure 5 Comparisons of picking time ratios of different pickers

\subsection{Detailed harvest process analysis}

After analyzing the picking and non-picking time ratio, efforts are put on the analysis of picking activity in terms of reaching, detaching, and transporting (Figure 6). Among the three activities, detaching is the most valuable, and it determines the harvest efficiency, with larger time ratio of detaching leading to higher harvest efficiency. Among the 4 pickers, the detaching time ratio ranges from $22 \%$ to $37 \%(30 \% \pm 6 \%)$. The variance in the detaching time ratio is mainly due to the difference of pickers. Overall the detaching time ratio is very low, which only accounts for $1 / 3$ of the total harvest time. Considering the high picking time ratio in the general analysis $(76 \%)$, the low detaching time ratio is the main reason leading to the lower harvest efficiency, because workers spent most of the time in reaching and transporting apples. So, in order to improve the overall harvest efficiency in the conventional harvest method, more efforts should be directed to decreasing the time ratio of reaching and transporting apples, and increasing the time ratio of detaching apples.
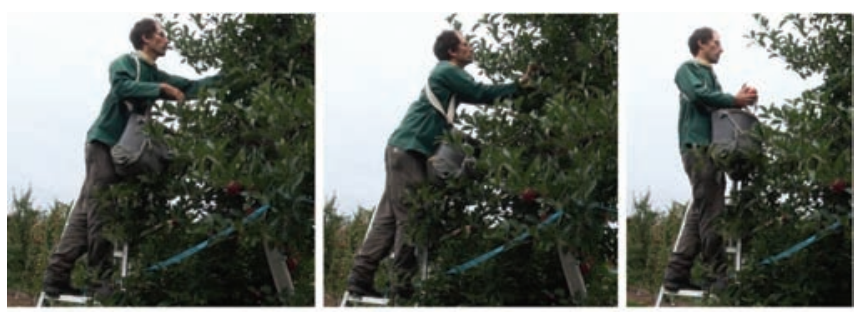

Figure 6 Detailed apple harvest activities as of reaching, detaching, and transporting apples from left to right photos

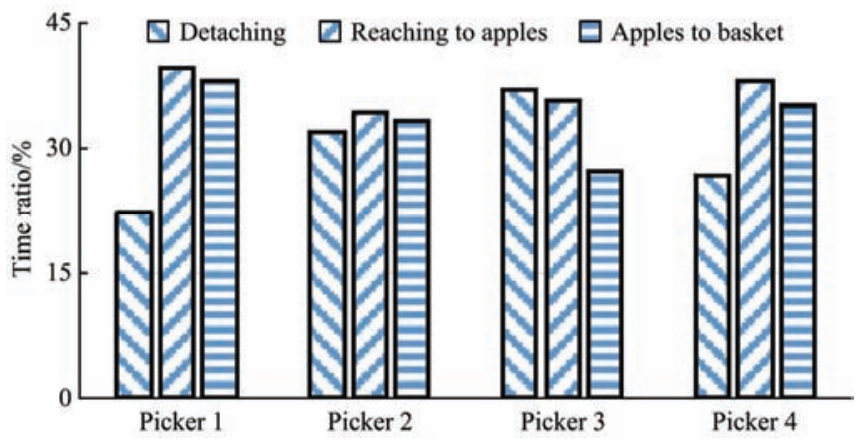

Figure 7 Detailed harvest process analysis of different pickers in terms of detaching, reaching, and transporting apples

\subsection{Valuable picking time ratio analysis}

Based on the general (picking and non-picking time) and the detailed (reaching, detaching, and transporting apples) analysis, the valuable picking time ratio is defined as the multiplication of picking time ratio and detaching time ratio (Equation (1)). The overall valuable picking time ratio could accurately reflect the harvest efficiency.

Valuable ratio $=$ picking time ratio $\times$ detaching time ratio (1)

The valuable time ratio for 4 different pickers are shown in Figure 8 , indicating the value ranging from $18 \%$ to $27 \%(22 \% \pm 5 \%)$ The result demonstrated theoretically that the overall low harvest efficiency of conventional harvest method. The highest value among the 4 different pickers is only $27 \%$, suggesting the picker spent $3 / 4$ of time in doing activities unrelated to apple picking.

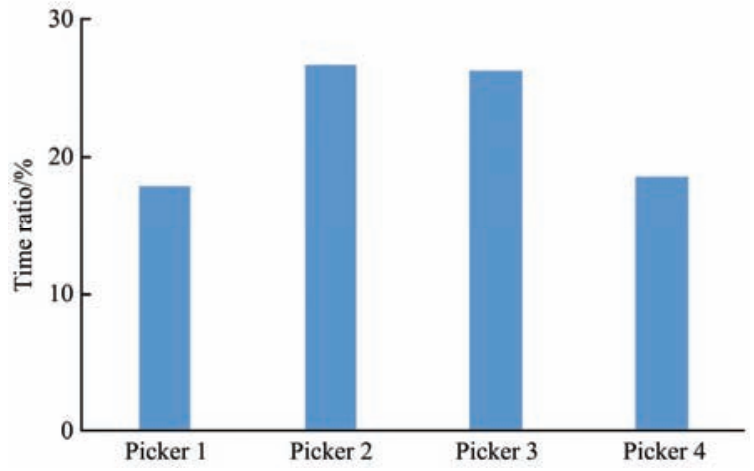

Figure 8 Valuable time ratio of different pickers in the conventional harvest method 


\section{Conclusions}

This study first provided a more detailed apple harvest activity categorization method to replace the previously used but too general approach. Then, the Rapid Upper Limb Assessment tool was chosen to evaluate the apple harvest process, which has an advantage of evaluating the posture in a more detailed approach than the previous used OWAS method. After using the new categorization method and RULA tool for inspection of apple harvest postures, the occupational injuries causing activities were identified, with the potential reason provided. It was quantitatively demonstrated that apple pickers averagely spent about $63 \%$ of harvest time under activities that would cause occupational injuries, indicating the harvest work is harmful to health. Since most of the occupational injury-inducing activities are associated with the use of ladders and buckets, using harvest platform with an innovative fruit transport system (e.g., vacuum and conveyor) to fully replace the use of ladders and buckets may be a solution to alleviate the occupation injuries. This study also theoretically explained the low efficiency of the conventional harvest method. General analysis of the harvest process in terms of picking and non-picking time ratios showed workers averagely spent $76 \%( \pm 7 \%)$ of harvest time in picking apples. Further analysis of picking activities in terms of reaching, detaching, and transporting apples showed pickers spent averagely $30 \%( \pm 6 \%)$ of time in detaching apples, which is the valuable time during apple harvest. The value time ratio (multiplication of picking time and detaching time ratio) was calculated as $22 \%( \pm 5 \%)$, theoretically demonstrated the low harvest efficiency of the traditional harvest method. To improve the harvest efficiency of the conventional harvest method, one potential solution is to increase the detaching time ratio, as well as decreasing the time ratios of reaching and detaching apples. It is therefore possible to design an innovative approach that could replace picker in manually delivering apples into a bucket. When workers are free from transporting apples into the bin, the time of reaching apples is also reduced significantly.

\section{[References]}

[1] Lu R, Zhang Z, Pothula A K. Innovative technology for apple harvest and in-field sorting. Fruit Qtly, 2017; 25(2): 11-14.

[2] He L, Schupp J. Sensing and automation in pruning of apple trees: A Review. Agronomy, 2018; 8(10): 211.

[3] Zhao D A, Lv J D, Ji W, Zhang Y, Chen Y. Design and control of an apple harvesting robot. Biosyst. Eng., 2011; 110(2): 112-122.

[4] Shamshiri R, Ishak W, Ismail W. Nonlinear tracking control of a two link oil palm harvesting robot manipulator. Int J Agric \& Biol Eng, 2012; 5(2): $1-11$.

[5] Baeten, J. Donne, K., Boedrij, S., Beckers, W., Claesen, E. Autonomous fruit picking machine: A robotic apple harvester. In Springer Tracts in Advanced Robotics, 2008; 42: 531-539.

[6] Shamshiri R R, Weltzien C, Hameed I A, Yule I J, Grift T E, Balasundram Chowdhary G. Research and development in agricultural robotics: A perspective of digital farming. Int J Agric \& Biol Eng, 2018; 11(4): 1-14.

[7] Shamshiri R R, Hameed I A, Karkee M, Weltzien C. Robotic Harvesting of Fruiting Vegetables: A Simulation Approach in V-REP, ROS and MATLAB. In Automation in Agriculture-Securing Food Supplies for Future Generations. InTech, 2018.

[8] Shamshiri R R, Hameed I A, Pitonakova L, Weltzien C, Balasundram S K, Yule I J, et al. Simulation software and virtual environments for acceleration of agricultural robotics: Features highlights and performance comparison. Int J Agric \& Biol Eng, 2018; 11(4): 15-31.

[9] Lehnert C, English A, McCool C, Tow A W, Perez T. Autonomous sweet pepper harvesting for protected cropping systems. IEEE Robot. Autom. Lett., 2017; 2(2): 872-879.
[10] Qureshi W S, Payne A, Walsh K B, Linker R, Cohen O, Dailey M N. Machine vision for counting fruit on mango tree canopies. Precision Agriculture, 2017; 18(2): 224-244.

[11] Mehta S S, Burks T F. Vision-based control of robotic manipulator for citrus harvesting. Comput. Electron. Agric., 2014; 102: 146-158.

[12] Wang L L, Zhao B, Fan J W, Hu X A, Wei S, Li Y S, et al. Development of a tomato harvesting robot used in greenhouse. Int J Agric \& Biol Eng, 2017; 10(4): 140-149.

[13] Zhang Z, Heinemann P H, Liu J, Baugher T A, Schupp J R. The development of mechanical apple harvesting technology: A review. Transactions of the ASABE, 2016; 59(5): 1165-1180.

[14] Pothula A, Zhang Z, Lu R. Design features and bruise evaluation of an apple harvest and infield presorting machine. Trans. ASABE, 2018; 61(3): 1135-1144.

[15] Silwal A, Davidson J R, Karkee M, Mo C, Zhang Q, Lewis K. Design, integration, and field evaluation of a robotic apple harvester. Journal of Field Robotics, 2017; 34(6): 1140-1159.

[16] Davidson J R, Silwal A, Hohimer C J, Karkee M, Mo C, Zhang Q. Proof-of-concept of a robotic apple harvester. IEEE/RSJ International Conference on Intelligent Robots and Systems (IROS), 2016; pp.634-639.

[17] He L, Schupp J. Sensing and automation in pruning of apple trees: A review. Agronomy, 2018; 8(10): 211.

[18] Zhang Z, Heinemann P, Liu J, Schupp J, Baugher T. Design, fabrication, and testing of a low-cost apple harvest-assist device. ASABE Paper No. 141839738. St. Joseph, MI: ASABE, 2014.

[19] Zhang Z, Pothula A, Lu R. Development and preliminary evaluation of a new bin filler for apple harvesting and infield sorting machine. Trans. ASABE, 2017; 60(6): 1839-1849.

[20] Zhang Z. Design, test, and improvement of a low-cost apple harvest-assis unit. PhD diss. State College, PA: Pennsylvania State University, Department of Agricultural and Biological Engineering, 2015.

[21] Zhang Z, Heinemann P, Liu J, Schupp J, Baugher T. Brush mechanism for distributing apples in a low-cost apple harvest-assist unit. Appl. Eng. in Agric., 2017; 33(2): 195-201.

[22] Feng J, Zeng L, He L. Apple fruit recognition algorithm based on multi-spectral dynamic image analysis. Sensors, 2019; 19(4): 949.

[23] Zhang Z, Zhang Z, Wang X, Liu H, Wang Y, Wang W. Models for economic evaluation of multi-purpose apple harvest platform and software development. I Int J Agric \& Biol Eng, 2019; 12(1): 74-83.

[24] Earle-Richardson G, Jenkins P L, Fulmer S, Mason C, Burdick P, May J J. An ergonomic intervention to reduce back strain among apple harvest workers in New York State. Applied Ergonomics, 2005; 36, 327-334.

[25] Fathallah F. A. Musculoskeletal disorders in labor-intensive agriculture. Applied ergonomics, 2010; 41(6): 738-743.

[26] Sakakibara H, Miyao M, Kondo T, Yamad S. Overhead work and shoulder-neck pain in orchard farmers harvesting pears and apples. Ergonomics, 1995; 38(4): 700-706.

[27] Bernard B. (1997). Musculoskeletal disorders and workplace factors: A critical review of epidemiologic evidence for work-related musculoskeletal disorders of the neck, upper extremity, and low back. Cincinnati, Ohio: National Institute for Occupational Safety and Health.

[28] Proto A R, Zimbalatti G. Risk Assessment of Repetitive Movements in the Citrus Fruit Industry. Journal of Agricultural Safety and Health, 2010; 16(4): 219-228.

[29] Earle-Richardson G, Fulmer S, Jenkins P, Mason C, Bresee C, May J. Ergonomic analysis of New York apple harvest work using a Posture-Activities-Tools-Handling (PATH) work sampling approach. Journal of Agricultural Safety and Health, 2004; 10(3): 163-176.

[30] Fulmer S, Punnett L, Slingerland D T, Earle-Richardson G. Ergonomic exposures in apple harvesting: Preliminary observations. American Journal of Industrial Medicine Supplement, 2002; 2: 3-9.

[31] Earle-Richardson G, Jenkins P L, Freivalds A, Burdick P, Park S, Lee C, et al. Laboratory evaluation of belt usage with apple buckets. American Journal of Industrial Medicine, 2006; 49: 23-29.

[32] Earle-Richardson G, Jenkins P L, Strogzta D, Bell E M, May J J. Development and initial assessment of objective fatigue measures for apple harvest work. Applied Ergonomics, 2006; 37: 719-727.

[33] Freivalds A, Park S, Lee C, Earle-Richardson G, Mason C, May J J. Effect of belt/bucket interface in apple harvesting. International Journal of Industrial Ergonomics, 2006; 36(11): 1005-1010. 
[34] McAtamney L, Corlett E N. RULA : a survey method for the investigation of work-related upper limb disorders. Applied Ergonomics, 1993; 24(2): 91-99.

[35] Dockrell S, O'Grady E, Bennett K, Mullarkey C, Mc Connell R, Ruddy R, Flannery C. An investigation of the reliability of Rapid Upper Limb Assessment (RULA) as a method of assessment of children's computing posture. Applied Ergonomics, 2012; 43: 632-636.

[36] Chen J D, Falkmer T, Parsons R, Buzzard J, Ciccarelli M. Impact of experience when using the Rapid Upper Limb Assessment to assess postural risk in children using information and communication technologies. Applied Ergonomics, 2014; 45(3): 398-405.

[37] Rahman C M. Study and analysis of work postures of workers working in a ceramic industry through rapid upper limb assessment (RULA). International Journal of Engineering, 2014; 5(3): 8269.

[38] Garcia P P N S, Polli G S, Campos J A. Working postures of dental students: ergonomic analysis using the Ovako Working Analysis System and rapid upper limb assessment. Med Lav, 2013; 104(6): 440-447.

[39] Zhang Z, Zhang Z H, Wang W, Liu H, Sun Z. The role of a new harvest platform in alleviation of apple workers' occupational injuries during harvest. Journal of Agricultural Safety and Health, 2019; 25(1): 11-24.

[40] Zhang Z, Pothula A K, Lu R. Economic analysis of a self-propelled apple harvest and in-field sorting machine for the apple industry. ASABE Paper No. 2456644. St. Joseph, MI: ASABE, 2016.

[41] Zhang Z, Pothula A K, Lu R. Development of a new bin filler for apple harvesting and infield sorting with a review of existing technologies. ASABE Paper No. 1700662, St. Joseph, MI: ASABE, 2017.

[42] Zhang Z, Luo Y, Robinson D. Reducing Food Poverty and Vulnerability among the Rural Elderly with Chronic Diseases: The Role of the New Rural Pension Scheme in China. International journal of environmental research and public health, 2018; 15(6): 1253.

[43] Zhang Z, Robinson D, Hite D. Racial Residential Segregation: Measuring Location Choice Attributes of Environmental Quality and Self-Segregation. Sustainability, 2018; 10(4): 1114.

[44] Zhang Z, Pothula A, Lu R. Improvements and evaluation of an infield bin filler for apple bruising and distributions. Trans. ASABE, 2019; 62(2): 271-280.

[45] Taylor F W. The principles of scientific management. Harper, 1914.

[46] Gilbreth F B. Scientific management in the hospital. Modern Hospital, 1914; 3: 321-324.

[47] Baumgart A, Neuhauser D. Frank and Lillian Gilbreth: Scientific management in the operating room. Quality and Safety in Health Care, 2009; 18(5): 413-415.

[48] Hendrich A, Chow M P, Skierczynski B A, Lu Z. A 36-hospital time and motion study: how do medical-surgical nurses spend their time? The Permanente Journal, 2008; 12(3): 25.

[49] Lan S, Wang X, Ma L. Optimization of assembly line based on work study. IE\&EM'09. 16th International Conference on Industrial Engineering and Engineering Management, IEEE, 2009; pp.813-816.

[50] Duran C, Cetindere A, Aksu Y E. Productivity improvement by work and time study technique for earth energy-glass manufacturing company. Procedia Economics and Finance, 2015; 26: 109-113.

[51] Moktadir M A, Ahmed S, Zohra F T, Sultana R. Productivity improvement by work study technique: a case on leather products industry of Bangladesh Ind. Eng. Manag., 2017; 6: 1-11. 